\title{
Percepções de indivíduos sobre o ato de cozinhar no ambiente doméstico: revisão integrativa de estudos qualitativos
}

\author{
Perceptions about home cooking: an integrative review \\ of qualitative studies
}

Ana Cláudia Mazzonetto (https://orcid.org/0000-0002-2009-592X) ${ }^{1}$

Moira Dean (https://orcid.org/0000-0002-9014-1266) ${ }^{2}$

Giovanna Medeiros Rataichesck Fiates (https://orcid.org/0000-0001-7830-1215) ${ }^{1}$

${ }^{1}$ Núcleo de Pesquisa de Nutrição em Produção de Refeições, Universidade Federal de Santa Catarina. R. Eng. Agronômico Andrei Cristian Ferreira s/n, Trindade. 88040-900 Florianópolis SC Brasil. ac.mazzonetto@gmail.com ${ }^{2}$ Institute for Global Food Security, School of Biological Sciences, Queen's University Belfast. Belfast Reino Unido.

\begin{abstract}
This study aimed to review qualitative studies on perceptions of home cooking. A systematic search was conducted in Scopus and SciELO databases using English and Portuguese terms related to home cooking, without date or language restrictions. Twenty-six articles, published between 2004 and 2017, investigated, whether as a primary objective or as a secondary finding, the perceptions of individuals on home cooking. More than half of the studies were conducted in English-speaking countries. Study participants included women and men, adults and seniors as well as residents of urban and rural areas, Eastern and Western countries, and developing and developed nations. Thematic analysis showed that home cooking has different interpretations and meanings in diverse contexts and revealed differences in how individuals plan and cook their meals at home. Cognitive, practical, affective, and emotional factors are the major motivators to home meal preparation. Having a cooking role model in the family, cooking confidence and skills, and living alone were reported as facilitators of home cooking. A better understanding of the heterogeneity of perceptions and meanings of home cooking can contribute to the development of effective and culturally appropriate interventions for stimulating healthy cooking habits.

Key words Meal, Qualitative research, Review, Cooking
\end{abstract}

Resumo O objetivo da presente revisão integrativa foi identificar estudos qualitativos que abordam a percepção de indivíduos sobre o ato de cozinhar no ambiente doméstico. Realizou-se busca sistemática em português e inglês nas bases de dados Scopus e SciELO, sem limite de data e idioma. Foram identificados e selecionados 26 artigos publicados entre os anos de 2004 e 2017 que exploraram como objetivo principal, ou como resultado secundário, perspectivas de indivíduos sobre o ato de cozinhar. Mais da metade foi realizada em países de língua inglesa. Os estudos foram conduzidos com homens e mulheres, adultos e idosos, residentes em área rural e urbana de países orientais $e$ ocidentais, desenvolvidos e em desenvolvimento. Análise temática dos estudos revelou que os indivíduos planejam e executam o ato de cozinhar de formas variadas e que cozinhar também é entendido de forma ampla e diversa. As motivações para cozinhar envolveram questões cognitivas, práticas, afetivas e emocionais. Diferentes influências foram identificadas. A presença (ou ausência) de modelo familiar, morar sozinho, ter ou não confiança e habilidade para cozinhar aparecem como facilitadores e barreiras. $O$ reconhecimento da heterogeneidade dos fatores que influenciam o ato de cozinhar podem informar a criação e o desenvolvimento de orientações e intervenções com a finalidade de estimulá-lo.

Palavras-chave Culinária, Pesquisa qualitativa, Revisão, Cozinhar 


\section{Introdução}

Nas sociedades urbanas ocidentais, as práticas de preparo de alimentos no ambiente doméstico estão mudando. Desde a metade do século XX, indivíduos têm dedicado menos tempo ao ato de cozinhar e as refeições preparadas em casa têm se tornado menos frequentes ${ }^{1-4}$. O declínio no preparo de alimentos pode estar relacionado a um consumo alimentar nutricionalmente inadequa$\mathrm{do}^{5-8}$.

Nesse sentido, estratégias de estímulo ao ato de cozinhar no ambiente doméstico visando melhoria na qualidade nutricional da alimentação estão ganhando visibilidade. No Brasil, orientações com intuito de estimular práticas culinárias são observadas em documentos oficiais, como o Marco de Referência de Educação Alimentar e Nutricional para Políticas Públicas, o qual, entre outros princípios, defende "a valorização da culinária enquanto prática emancipatória e o preparo do próprio alimento como promotor da autonomia dos indivíduos e facilitador do exercício das dimensões sensoriais, cognitivas e simbólicas da alimentação"9(p.68). Já o Guia Alimentar para a População Brasileira (GAPB), ao orientar e estimular a prática de uma alimentação adequada e saudável, recomenda que o indivíduo "prefira sempre alimentos in natura ou minimamente processados e preparações culinárias à alimentos ultraprocessados". Alimentos minimamente processados são alimentos in natura que foram submetidos a processos industriais, mas que não envolvam a agregação de sal, açúcar, óleos, gorduras ou outras substâncias. Alimentos ultraprocessados são produtos submetidos a diversas etapas e técnicas de processamento e com muitos ingredientes, como sal, açúcar, gorduras e substâncias de uso exclusivamente industrial ${ }^{10,11}$.

$\mathrm{Na}$ maioria das vezes, os alimentos in natura ou minimamente processados, precisam ser selecionados, pré-preparados, temperados, cozidos, combinados a outros alimentos e apresentados na forma de preparações para que possam ser consumidos $^{12}$, portanto considera-se que o ato cozinhar seja necessário para o atendimento dessas recomendações. Internacionalmente, estudos de revisão identificaram a retomada do ensino de culinária nas escolas e a realização de intervenções comunitárias entre as estratégias destinadas a estimular o ato de cozinhar ${ }^{13,14}$.

Apesar das crescentes estratégias estimulando o ato de cozinhar, pesquisadores argumentam que existem poucos detalhes sobre essa prática e que ela abrange uma maior complexidade do que se supõe $\mathrm{e}^{15-18}$. Short ${ }^{15,16}$ destaca que não existe uma relação clara entre saber cozinhar e a efetivação do ato, propriamente dito. Meah e Watson ${ }^{17}$ consideram que é necessário compreender os processos envolvidos no preparo de uma refeição e na dinâmica de desenvolvimento do hábito de cozinhar. Complementarmente, Halkier ${ }^{18}$ argumenta que o ato de cozinhar deve ser compreendido como um fenômeno composto por variabilidades e sutilezas e que sem essa compreensão corremos o risco de atuar de maneira simplista e conduzir iniciativas normativas e irreais, subestimando a complexidade que é cozinhar.

Pesquisas com abordagem qualitativa são as mais indicadas para compreender fenômenos e a percepção de indivíduos com relação a eles, pois buscam investigar sentimentos, pensamentos e experiências $^{19}$. Deste modo, o objetivo do presente artigo é realizar uma revisão integrativa de estudos qualitativos sobre o ato de cozinhar no ambiente doméstico.

\section{Método}

Realizou-se uma revisão integrativa de acordo com as seguintes etapas: elaboração de questão norteadora, estabelecimento de critérios de inclusão para seleção dos artigos, extração e síntese dos dados, análise dos dados, discussão dos resultados e a apresentação da revisão ${ }^{20}$.

Utilizou-se a seguinte questão norteadora: "Quais as percepções de indivíduos sobre o ato de cozinhar no ambiente doméstico identificadas em estudos qualitativos?". Para definição dos termos de busca foram utilizados descritores $\mathrm{Me}$ dical Subject Headings (MeSH) e Descritores em Saúde (DeCS). Adicionalmente, antes da definição final dos termos de busca, foram realizadas buscas exploratórias a fim de identificar palavras-chave utilizadas nos artigos e assim compor os grupos de termos conforme apresentado no Quadro 1.

Busca sistemática em português e inglês foi realizada em 09 de janeiro de 2017 e atualizada em 18 de maio de 2018 nas bases de dados Scopus e SciELO, sem limitar data ou idioma de publicação dos artigos. A base de dados Scopus foi escolhida por se tratar da maior fonte de resumos e citações da literatura com revisão por pares. A busca na base SciELO buscou garantir a captação de estudos brasileiros. A busca no Scopus foi realizada com termos em inglês e restringiu-se aos campos de título, resumo e palavras-chave. Foram utilizados dois grupos de termos, o primeiro 
Quadro 1. Descritores e palavras-chave usados na busca sistemática de estudos qualitativos sobre o ato de cozinhar no ambiente doméstico.

\begin{tabular}{|c|c|}
\hline Grupo de termos & Termos \\
\hline \multirow{4}{*}{$\begin{array}{l}\text { Ato de cozinhar } \\
\text { no ambiente } \\
\text { doméstico }\end{array}$} & $\begin{array}{l}\text { Descritores MeSH: } \\
\text { cooking, food handling, meal }\end{array}$ \\
\hline & 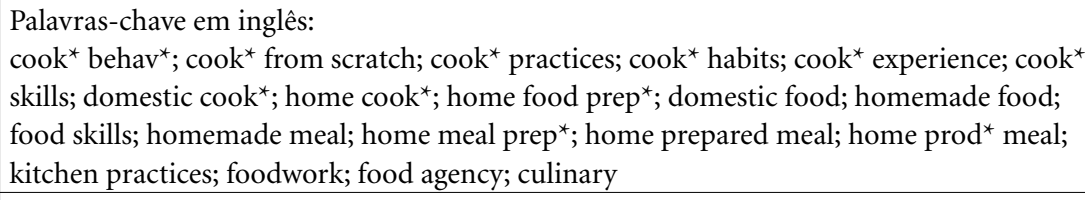 \\
\hline & $\begin{array}{l}\text { Descritores em Ciências da Saúde (DeCS): } \\
\text { Culinária }\end{array}$ \\
\hline & $\begin{array}{l}\text { Palavras-chave em português: } \\
\text { cozinhar; refeição; comida caseira }\end{array}$ \\
\hline \multirow[t]{2}{*}{$\begin{array}{l}\text { Estudos } \\
\text { qualitativos }\end{array}$} & $\begin{array}{l}\text { Descritores MeSH: } \\
\text { qualitative research; focus group; health knowledge, attitudes, practice }\end{array}$ \\
\hline & $\begin{array}{l}\text { Palavras-chave em inglês: } \\
\text { qualitative; semi-structured interview; in depth interview; narrative interview; life course } \\
\text { perspective; life course interview; open ended interview; ethnography; focus groups; } \\
\text { perception; meaning; belief; motivat }{ }^{\star} \text {; benefit; barrier; enjoyment; involvement; pleasure; } \\
\text { emotion; identit }{ }^{*}\end{array}$ \\
\hline
\end{tabular}

Fonte: as autoras.

relacionado ao ato de cozinhar no ambiente doméstico e o segundo relacionado a estudos qualitativos. Utilizou-se também o operador booleano and not com termos relacionados a temas que não eram de interesse da presente pesquisa a fim de restringir a busca.

A busca na base SciELO foi realizada em português e inglês e foram usados apenas os termos relacionados ao ato de cozinhar no ambiente doméstico, não sendo necessária a realização de combinações em decorrência do pequeno número de publicações identificadas.

Os artigos foram selecionados com base nos seguintes critérios de inclusão: ser artigo publicado em revista com revisão por pares; apresentar texto completo para o acesso; tratar de estudo com abordagem qualitativa; apresentar resultados relacionados ao ato de cozinhar no ambiente doméstico.

A partir da busca sistemática foram identificados 476 artigos, os quais foram importados para um gerenciador de referências. Desses, 50 foram selecionados a partir da leitura do título e resumos. Após a leitura completa do texto, 24 artigos foram excluídos pelos seguintes motivos: 10 por apresentarem abordagem predominantemente quantitativa embora utilizassem termos que remetessem à pesquisa qualitativa tais como percep̧̧ão ou significados; 10 por discutirem alimentação, mas não efetivamente o ato de cozi- nhar; 3 por tratarem-se de estudos teórico-metodológicos e 01 por tratar unicamente de questões de higiene relacionadas ao ato de cozinhar no ambiente doméstico. Assim, foram identificados 26 artigos com abordagem qualitativa que exploraram como objetivo principal ou apresentaram como resultado secundário, perspectivas de indivíduos sobre o ato de cozinhar. O fluxograma de seleção de artigos pode ser identificado na Figura 1. Os resultados dos artigos foram traduzidos para o português e transcritos para um documento do Microsoft Word 2016 ${ }^{\circledR}$ formando um corpus. Realizou-se análise temática indutiva seguindo as seis etapas propostas por Braun e Clark ${ }^{21}$ : familiarização com o material textual, codificação sistemática dos dados, agrupamento dos códigos em temas, revisão e agrupamento de temas, refinamento dos temas, redação dos resultados. A análise temática foi conduzida pela primeira autora e revisada pela segunda autora.

\section{Resultados}

Os 26 artigos selecionados foram publicados entre os anos de 2004 e 2017 e conduzidos em doze locais diferentes, sendo que dois terços $(\mathrm{n}=$ 17) foram realizados em países de língua inglesa. Dos 26 artigos, 14 tiveram o objetivo principal relacionado diretamente ao ato de cozinhar. Por 


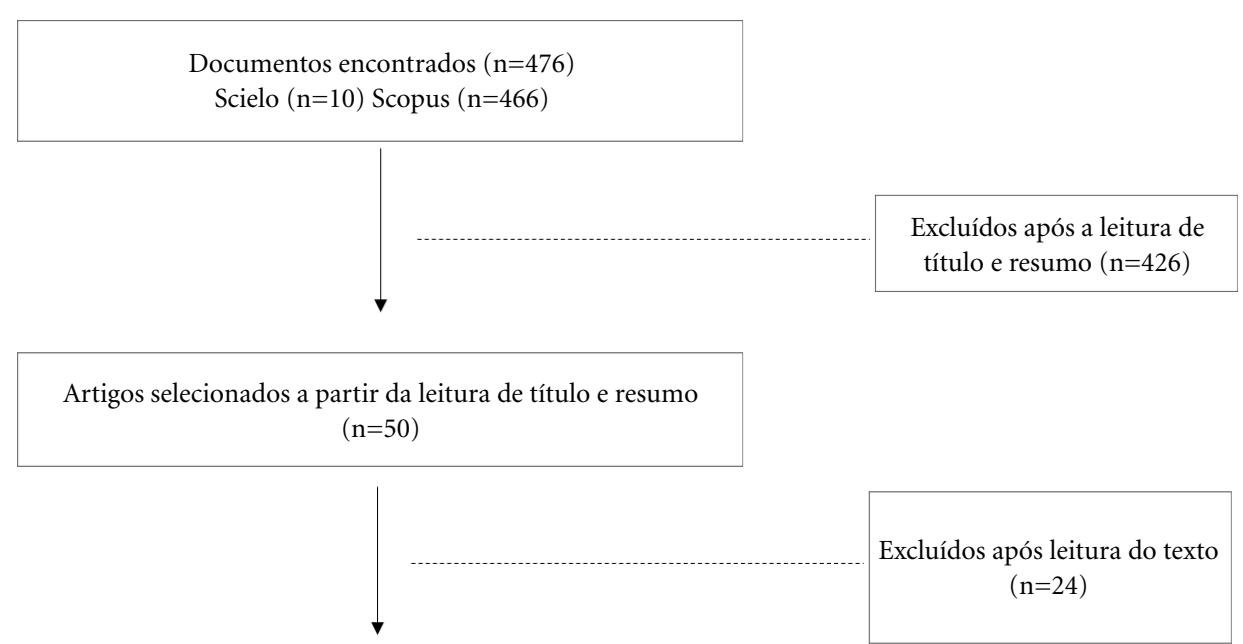

Artigos sobre cozinhar com abordagem qualitativa $(n=26)$

Figura 1. Fluxograma de seleção de artigos qualitativos sobre o ato de cozinhar no ambiente doméstico. Fonte: as autoras.

outro lado, esse não foi o principal objetivo dos demais artigos. No entanto, apresentaram nos resultados, ainda que brevemente, percepções dos participantes sobre o ato de cozinhar (Quadro 2).

A análise dos estudos no sentido de identificar percepções dos participantes sobre o ato de cozinhar levou à identificação de três grandes temas: Diversidade na interpretação e efetivação do ato de cozinhar; Motivações para cozinhar; Facilitadores e barreiras para cozinhar.

\section{Diversidade na interpretação e efetivação do ato de cozinhar}

Os artigos demonstram que indivíduos interpretam e efetivam o ato de cozinhar de maneiras diferentes e variadas entre si. Quatro estudos analisados contribuíram para a criação deste tema, nos quais foi destacada e discutida essa variedade a partir de diferentes perspectivas ${ }^{18,22-24}$. Dois deles investigaram especificamente a compreensão e definição de termos relacionados a cozinhar: home-cooking (cozinhar em casa) ${ }^{24} \mathrm{e}$ cooking from scratch (cozinhar do zero) ${ }^{23,25}$. Os outros dois destacaram as diferenças no planejamento, organização e execução ${ }^{18,22}$.

Nos Estados Unidos, Wolfson et al. ${ }^{24}$ exploraram como indivíduos definiam cozinhar em casa. As definições variaram consideravelmente e abrangeram diferentes níveis de entendimento. $\mathrm{O}$ entendimento sobre o que significa cozinhar em casa variou desde "all scratch cooking" a "qualquer coisa feita em casa" (incluindo refeições prontas, congeladas $)^{24}$.

Na Irlanda do Norte e na República da Irlanda, Lavelle et al. ${ }^{23}$ identificaram, como indivíduos definiam, especificamente, cozinhar do zero. Esses autores também observaram que as percepções sobre cozinhar do zero abrangiam uma variedade de entendimentos do termo: do tradicional (usando exclusivamente ingredientes naturais, frescos ou crus) para uma versão mais inclusiva, que incorporou alguns alimentos pré -elaborados (como filés de peixe congelados) ${ }^{23}$. Assim, observa-se nos dois estudos uma variedade na compreensão e definição de termos relacionados a cozinhar que vão de versões mais restritivas a versões mais abrangentes ${ }^{23,24}$.

Essa diversidade sobre o que seria o ato de cozinhar observada nos dois estudos supracitados é endossada pelo estudo de Gatley ${ }^{22}$. Segundo o autor, o ato de cozinhar depende sobremaneira do contexto em que o indivíduo está inserido. Ao estudar as rotinas e experiências culinárias de homens e mulheres na França e Grã-Bretanha, o autor identificou que quando solicitados para descrever os alimentos preparados em casa, quase metade dos respondentes britânicos descreveu 
Quadro 2. Informações dos artigos selecionados em busca sistemática de estudos qualitativos sobre o ato de cozinhar no ambiente doméstico, apresentados em ordem crescente segundo ano de publicação.

\begin{tabular}{|c|c|c|}
\hline Autores (ano), País & Sujeitos & Objetivos \\
\hline \multicolumn{3}{|c|}{ Artigos com objetivo relacionado diretamente à percepção sobre o ato de cozinhar $(n=14)$} \\
\hline $\begin{array}{l}\text { Halkier }(2009)^{18}, \\
\text { Dinamarca }\end{array}$ & $\begin{array}{l}6 \text { mulheres, } 25 \text { e } 50 \text { anos, } \\
\text { diversidade sociodemográfica }\end{array}$ & $\begin{array}{l}\text { Discutir como as práticas culinárias de mulheres as } \\
\text { posicionam com relação ao preparo de refeições caseiras }\end{array}$ \\
\hline $\begin{array}{l}\text { Engler-Stringer } \\
(2010)^{31}, \text { Canadá }\end{array}$ & $\begin{array}{l}22 \text { mulheres, } 18 \text { a } 35 \text { anos, } \\
\text { baixa renda }\end{array}$ & $\begin{array}{l}\text { Elucidar as práticas sociais relacionadas ao preparo de } \\
\text { alimentos a partir da análise do ambiente alimentar } \\
\text { doméstico de mulheres morando em Montreal }\end{array}$ \\
\hline $\begin{array}{l}\text { Meah e Watson } \\
(2011)^{17} \text {, Reino } \\
\text { Unido }\end{array}$ & $\begin{array}{l}2 \text { famílias ( } 2 \text { gerações de cada } \\
\text { família) }\end{array}$ & $\begin{array}{l}\text { Tornar visíveis tanto as memórias sobre cozinhar como } \\
\text { os significados de práticas reais de indivíduos enquanto } \\
\text { interagem com alimentos e outros objetos relacionados }\end{array}$ \\
\hline $\begin{array}{l}\text { Simmons e } \\
\text { Chapman }(2012)^{29} \text {, } \\
\text { Canadá }\end{array}$ & $\begin{array}{l}22 \text { famílias com diversidade } \\
\text { socioeconômica }\end{array}$ & $\begin{array}{l}\text { Explorar a perspectiva de pais e filhos sobre a } \\
\text { importância de ser apto a cozinhar }\end{array}$ \\
\hline $\begin{array}{l}\text { Sharif et al. }(2013)^{44} \\
\text { Malásia }\end{array}$ & $\begin{array}{l}\text { Indivíduos envolvidos no } \\
\text { preparo de refeições para } \\
\text { celebrações }\end{array}$ & $\begin{array}{l}\text { Identificar e reconhecer a transferência do conhecimento } \\
\text { culinário tradicional para as gerações mais jovens na } \\
\text { Malásia }\end{array}$ \\
\hline $\begin{array}{l}\text { Gatley et al. }(2014)^{35} \text {, } \\
\text { Reino Unido e França }\end{array}$ & $\begin{array}{l}27 \text { indivíduos, } 23 \text { a } 73 \text { anos, } \\
\text { homens e mulheres }\end{array}$ & $\begin{array}{l}\text { Explorar as atitudes e comportamentos em relação ao } \\
\text { hábito de cozinhar na França e na Grã-Bretanha }\end{array}$ \\
\hline $\begin{array}{l}\text { Jones et al. }(2014)^{26} \\
\text { Estados Unidos }\end{array}$ & $\begin{array}{l}239 \text { estudantes de } 2 \\
\text { universidades, maioria } \\
\text { mulheres }\end{array}$ & $\begin{array}{l}\text { Identificar motivações e barreiras para o preparo } \\
\text { de alimentos em casa versus a compra de alimentos } \\
\text { pré-preparados ou o consumo de alimentos em um } \\
\text { restaurante }\end{array}$ \\
\hline $\begin{array}{l}\text { Gram et al. }(2015)^{43} \text {, } \\
\text { Dinarmaca }\end{array}$ & $\begin{array}{l}75 \text { estudantes, } 18 \text { a } 25 \text { anos, } \\
\text { maioria mulheres }\end{array}$ & $\begin{array}{l}\text { Examinar como a identidade familiar relacional é } \\
\text { vivenciada em um período de transição por jovens } \\
\text { universitários que estão estabelecendo suas novas vidas, } \\
\text { vivendo e cozinhando sozinhos }\end{array}$ \\
\hline $\begin{array}{l}\text { Neuman et al. } \\
(2015)^{38} \text {, Suécia }\end{array}$ & 31 homens, 22 a 88 anos & $\begin{array}{l}\text { Explorar as histórias de homens suecos sobre cozinhar } \\
\text { como parte de suas vidas cotidianas e pontos de transição } \\
\text { em suas vidas e a relação com noção mais amplas de } \\
\text { alimentação e igualdade de gênero }\end{array}$ \\
\hline $\begin{array}{l}\text { Gatley }(2016)^{22} \text {, } \\
\text { Reino Unido e } \\
\text { França }\end{array}$ & $\begin{array}{l}13 \text { franceses e } 14 \text { britânicos; } \\
\text { homens e mulheres }\end{array}$ & $\begin{array}{l}\text { Explorar as rotinas, as experiências cotidianas e } \\
\text { as atitudes sobre cozinhar e comer comparando o } \\
\text { significado de tais culturas culinárias na França e na } \\
\text { Grã-Bretanha }\end{array}$ \\
\hline $\begin{array}{l}\text { Lavelle et al. }(2016)^{23} \\
\text { Irlanda do Norte e } \\
\text { República da Irlanda }\end{array}$ & $\begin{array}{l}27 \text { participantes, } 18 \text { a } 58 \\
\text { anos, homens e mulheres }\end{array}$ & $\begin{array}{l}\text { Explorar qualitativamente como os indivíduos } \\
\text { definem cooking from scratch e quais são as barreiras } \\
\text { e facilitadores para cozinhar a partir de ingredientes } \\
\text { básicos }\end{array}$ \\
\hline $\begin{array}{l}\text { Wolfson et al. } \\
(2016)^{24}, \text { Estados } \\
\text { Unidos }\end{array}$ & $\begin{array}{l}53 \text { participantes, maioria } \\
\text { mulheres, } 2 \text { comunidades } \\
\text { (média-alta/baixa renda) }\end{array}$ & $\begin{array}{l}\text { Examinar a percepção de adultos sobre os conceitos } \\
\text { relacionados a cozinhar }\end{array}$ \\
\hline $\begin{array}{l}\text { Bostic e McClain } \\
(2017)^{27}, \text { Estados } \\
\text { Unidos }\end{array}$ & $\begin{array}{l}17 \text { idosos, homens e } \\
\text { mulheres }\end{array}$ & $\begin{array}{l}\text { Explorar experiências culinária de idosos vivendo nos } \\
\text { Estados Unidos da América }\end{array}$ \\
\hline $\begin{array}{l}\text { Mills et al. }(2017)^{28} \text {, } \\
\text { Reino Unido }\end{array}$ & 18 adultos, maioria mulheres & $\begin{array}{l}\text { Estudar percepções, experiências e práticas de preparo } \\
\text { de refeições no ambiente doméstico entre adultos } \\
\text { ingleses }\end{array}$ \\
\hline \multicolumn{3}{|c|}{ Artigos que apresentaram resultados relacionados à percepção sobre o ato de cozinhar $(n=12)$} \\
\hline $\begin{array}{l}\text { Moisio et al. }(2004)^{32}, \\
\text { Estados Unidos }\end{array}$ & $\begin{array}{l}65 \text { indivíduos, } 36 \text { a } 60 \text { anos, } \\
\text { homens e mulheres }\end{array}$ & $\begin{array}{l}\text { Examinar o papel da comida caseira na construção da } \\
\text { identidade familiar }\end{array}$ \\
\hline $\begin{array}{l}\text { Johnson et al. } \\
(2010)^{39}, \text { Estados } \\
\text { Unidos }\end{array}$ & $\begin{array}{l}7 \text { mulheres, } 26 \text { a } 42 \text { anos, } \\
\text { com pelo menos } 1 \text { filho }\end{array}$ & $\begin{array}{l}\text { Compreender como mães fazem escolhas alimentares } \\
\text { para suas famílias }\end{array}$ \\
\hline
\end{tabular}




\begin{tabular}{|c|c|c|c|}
\hline 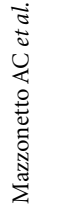 & $\begin{array}{l}\text { Quadro 2. Informaçõe } \\
\text { cozinhar no ambiente }\end{array}$ & $\begin{array}{l}\text { s dos artigos selecionados em } \mathrm{b} \\
\text { doméstico, apresentados em or }\end{array}$ & $\begin{array}{l}\text { usca sistemática de estudos qualitativos sobre o ato de } \\
\text { lem crescente segundo ano de publicação. }\end{array}$ \\
\hline & Autores (ano), País & Sujeitos & Objetivos \\
\hline & $\begin{array}{l}\text { Diez-Garcia e Castro } \\
(2011)^{30}, \text { Brasil }\end{array}$ & $\begin{array}{l}30 \text { famílias, classe popular e } \\
\text { classe média, pelo menos } 1 \\
\text { pessoa com hipertensão }\end{array}$ & $\begin{array}{l}\text { Conhecer o impacto da incorporação da restrição } \\
\text { alimentar pela família, focalizando aspectos da culinária } \\
\text { sob condições restritivas ao uso do sal e entendendo este } \\
\text { procedimento como uma manifestação de autocuidado }\end{array}$ \\
\hline & $\begin{array}{l}\text { Meah e Jackson } \\
(2013)^{40}, \text { Reino } \\
\text { Unido }\end{array}$ & $\begin{array}{l}\text { Oito famílias, } 17 \text { a } 92 \text { anos, } \\
\text { homens e mulheres }\end{array}$ & $\begin{array}{l}\text { Explorar até que ponto as mudanças nas práticas } \\
\text { de cozinha levaram a uma “democratização" da } \\
\text { domesticidade, sinalizando maior igualdade de gênero }\end{array}$ \\
\hline & $\begin{array}{l}\text { Szabo }(2014)^{34}, \\
\text { Canadá }\end{array}$ & \multirow{2}{*}{$\begin{array}{l}30 \text { homens, } 26 \text { a } 58 \text { anos, } \\
\text { responsáveis por preparar } \\
\text { pelo menos metade das } \\
\text { refeições em seus domicílios }\end{array}$} & $\begin{array}{l}\text { Investigar as dicotomias de gênero a partir das } \\
\text { experiências de homens responsáveis por cozinhar }\end{array}$ \\
\hline & $\begin{array}{l}\text { Szabo }(2014)^{36}, \\
\text { Canadá }\end{array}$ & & $\begin{array}{l}\text { Compreender, entre homens com responsabilidades na } \\
\text { cozinha doméstica, como as masculinidades podem ser } \\
\text { afetadas pela mudança dos papéis de gênero em torno } \\
\text { da comida }\end{array}$ \\
\hline & Liu $(2016)^{37}$, China & 3 casais & $\begin{array}{l}\text { Analisar relações entre casais a partir de suas relações na } \\
\text { organização de refeições diárias e do trabalho doméstico } \\
\text { relacionado ao preparo de alimentos }\end{array}$ \\
\hline & $\begin{array}{l}\text { Machin et al. } \\
(2017)^{45}, \text { Uruguai }\end{array}$ & $\begin{array}{l}91 \text { participantes, maioria } \\
\text { mulheres }\end{array}$ & $\begin{array}{l}\text { Identificar barreiras e facilitadores para adoção do novo } \\
\text { guia alimentar para a população uruguaia }\end{array}$ \\
\hline & $\begin{array}{l}\text { Lane et al. }(2014)^{47} \text {, } \\
\text { Reino Unido }\end{array}$ & $\begin{array}{l}40 \text { mulheres, } 65 \text { anos ou } \\
\text { mais, que reduziram o } \\
\text { preparo de refeições }\end{array}$ & $\begin{array}{l}\text { Descobrir, em mulheres idosas que renunciaram à } \\
\text { responsabilidade primária pelo preparo de refeições, } \\
\text { o impacto sobre os significados da alimentação, o } \\
\text { engajamento social e o bem-estar }\end{array}$ \\
\hline & $\begin{array}{l}\text { Parsons }(2016)^{33}, \\
\text { Reino Unido }\end{array}$ & $\begin{array}{l}75 \text { respondentes, } 27 \text { a } 85 \\
\text { anos, maioria mulheres e da } \\
\text { classe média }\end{array}$ & $\begin{array}{l}\text { Demonstrar como práticas alimentares cotidianas } \\
\text { continuam a ser influenciados pelas interseções de } \\
\text { gênero e classe }\end{array}$ \\
\hline & $\begin{array}{l}\text { Bailey }(2017)^{42} \text {, } \\
\text { Holanda }\end{array}$ & $\begin{array}{l}30 \text { migrantes indianos } \\
\text { vivendo na Holanda, } 25 \text { a } 50 \\
\text { anos, maioria homens }\end{array}$ & $\begin{array}{l}\text { Analisar as práticas alimentares e sua relação com } \\
\text { pertencimento, comensalidade e cuidado, entre } \\
\text { migrantes indianos }\end{array}$ \\
\hline & $\begin{array}{l}\text { Hertz e Halkier } \\
(2017)^{46} \text {, Dinamarca }\end{array}$ & $\begin{array}{l}13 \text { indivíduos, com filho(s), } \\
\text { maioria mulheres }\end{array}$ & $\begin{array}{l}\text { Compreender como como famílias dinamarquesas } \\
\text { incluem o uso de meal box schemes em suas rotinas } \\
\text { diárias }\end{array}$ \\
\hline
\end{tabular}

Fonte: as autoras.

preparações prontas para o consumo e outros alimentos de conveniência. Em contraste, embora os participantes franceses relatassem a necessidade de preparar refeições rapidamente e utilizar itens pré-elaborados, nenhum deles descreveu o uso de preparações prontas, com exceção da pizza pronta para as crianças ${ }^{22}$.

O estudo de Halkier ${ }^{18}$ também demonstra que indivíduos desenvolvem maneiras diferentes de planejar, organizar, e executar o ato de cozinhar. Ao analisar, na Dinamarca, as práticas culinárias de seis mulheres entre 25 e 50 anos, de diferentes espaços geográficos, estruturas familiares e níveis educacionais, diferentes estilos culinários foram identificados, os quais se distanciavam em alguns aspectos e se aproximavam em outros, demonstrando assim diferenças e pontos comuns na forma como cada uma delas cozinhava. Dessa forma, cozinhar podia ser baseado em extenso planejamento ou em uma noção naturalizada sobre como fazer para preparar uma refeição, não sendo necessária muita reflexão. A organização das compras também variava, podendo ocorrer, sem planejamento, com objetivo de ter ingredientes com os quais improvisar no momento de cozinhar ou baseadas em uma predefinição do tipo e quantidades de alimentos a serem consumidos diariamente. Saber cozinhar podia ser baseado em experiências obtidas desde a infância ou apenas mais tarde, por necessidade. Receitas podiam ser consideradas necessárias para a execução ou servir apenas de inspiração, sendo adaptadas de acordo com vontades ou ingredientes disponíveis ${ }^{18}$. 

ca da Irlanda ${ }^{23}$, cozinhar permitia o controle sobre sua alimentação e da família, definindo quais alimentos seriam consumidos e quais excluídos. Indivíduos canadenses consideraram que essa prática permite, por exemplo, que pais controlem os ingredientes presentes na alimentação dos filhos, cumprindo assim o seu papel de "guardiões nutricionais" e decidindo ativamente quais alimentos são usados nas refeições familiares ${ }^{29}$.

Entre indivíduos brasileiros ${ }^{30}$, canadenses $^{29,31}$, estadunidenses ${ }^{24,26,27,32}$ e britânicos ${ }^{33}$ cozinhar $^{2}$ também possibilitava o controle de gastos e o sustento da família mesmo com recursos alimentares e financeiros escassos, permitindo maior controle do orçamento doméstico.

Indivíduos canadenses relataram que cozinhar faz insurgir sentimentos de autossuficiência $^{29}$ e consideraram uma habilidade que todos deveriam possuir ${ }^{34}$. Indivíduos canadenses relataram que saber cozinhar era um sinal de independência e responsabilidade pelo preparo de suas próprias refeições ${ }^{29}$.

Homens e mulheres de diferentes países, tais como Canadá, Estados Unidos, Reino Unido, França e China ${ }^{26,28,29,32,33,35-37}$ consideraram que cozinhar pode ser uma forma de se conectar com o outro, estreitando relações e expressando amor e cuidado entre aquele que produz o alimento e aquele que o consome.

Indivíduos britânicos relataram sentir pra$\operatorname{zer}^{28}$ e valorizar o aspecto social de cozinhar ${ }^{28,35}$, especialmente aos finais de semana e descrevem que muitas vezes se trata de uma atividade de lazer que envolve a presença de amigos e familiares $^{35}$. Em estudos conduzidos com homens e mulheres estadunidenses, o ato de cozinhar foi motivado pelo prazer em se dedicar a essa prática $^{26,27,32}$. Homens suecos e canadenses relataram que cozinhar poderia ser uma atividade de lazer e uma forma de experimentação e demonstração criatividade $\mathrm{e}^{33,34,36,38}$.

Indivíduos estadunidenses ${ }^{24}$, britânicos e franceses ${ }^{35}$ definiram o ato de cozinhar como uma atividade prioritária ${ }^{24} \mathrm{e}$ incorporada na rotina diária $^{35}$. Homens suecos relataram que cozinhar era algo imprescindível para atender as necessidades

$\operatorname{cotidianas~}^{38}$. Indivíduos britânicos, especialmente mães, identificaram a responsabilidade pelo provimento de alimentos aos filhos como importante motivação para cozinhar ${ }^{28}$.

Cozinhar foi considerado tanto como uma forma de manter tradições familiares e culturais, quanto como uma maneira de romper com essas tradições e explorar novas formas de comer e cozinhar $^{17,27,29,39-42}$. Por exemplo, em estudo realizado com mulheres, nos Estados Unidos, algumas relataram que buscavam manter os hábitos culinários das mães, enquanto outras não gostavam de carregar os hábitos maternos e mostravam uma atitude de ressentimento com relação a isso ${ }^{39}$. Outro estudo estadunidense, conduzido com idosos, identificou que, alguns deles relatavam orgulho em reproduzir preparações transmitidas entre membros da famíliaa ${ }^{27}$. Na Dinamarca, adultos jovens relataram que, ao cozinhar, modificavam alguns hábitos na alimentação e tentavam influenciar mudanças também nos pais ${ }^{43}$. Em estudo observacional, conduzido na Malásia, identificou-se que cozinhar com as mães e outros membros da família era uma maneira de transmitir técnicas e de fortalecer relações familiares ${ }^{44}$. Na Holanda, migrantes indianos relataram que cozinhar era parte central para a noção de pertencimento, auxiliando-os a lidar com a saída de casa e recriar o vínculo familiar, utilizando temperos, condimentos e utensílios usados pelas mães ${ }^{42}$.

\section{Facilitadores e barreiras para cozinhar}

Os facilitadores e barreiras para cozinhar mencionados pelos participantes nos estudos são apresentados na Figura 3.

Indivíduos estadunidenses ${ }^{26,27}$, canadenses $^{29}$, dinamarqueses $^{18,43}$ e irlandeses ${ }^{23}$ destacaram a importância de ter um modelo familiar para o preparo de refeições, aprendendo a cozinhar com os pais ou com outros membros da família. Halkier $^{18}$, na Dinamarca, identificou, entre algumas mulheres que aprenderam a cozinhar na infância, uma noção naturalizada sobre como cozinhar $^{18}$. Em outro estudo na Dinamarca, os participantes consideraram seus pais como modelos positivos para o hábito de planejar as refeições com antecedência e usar especiarias e vegetais no preparo das refeições ${ }^{43}$. Por outro lado, adultos jovens estadunidenses expressaram um desejo de que seus pais tivessem preparado mais alimentos em casa e assim eles saberiam preparar refeições com confiança ${ }^{26}$.

Indivíduos britânicos ${ }^{35}$, irlandeses ${ }^{23}$, estadunidenses $^{26}$ e uruguaios ${ }^{45}$ destacaram a importância 


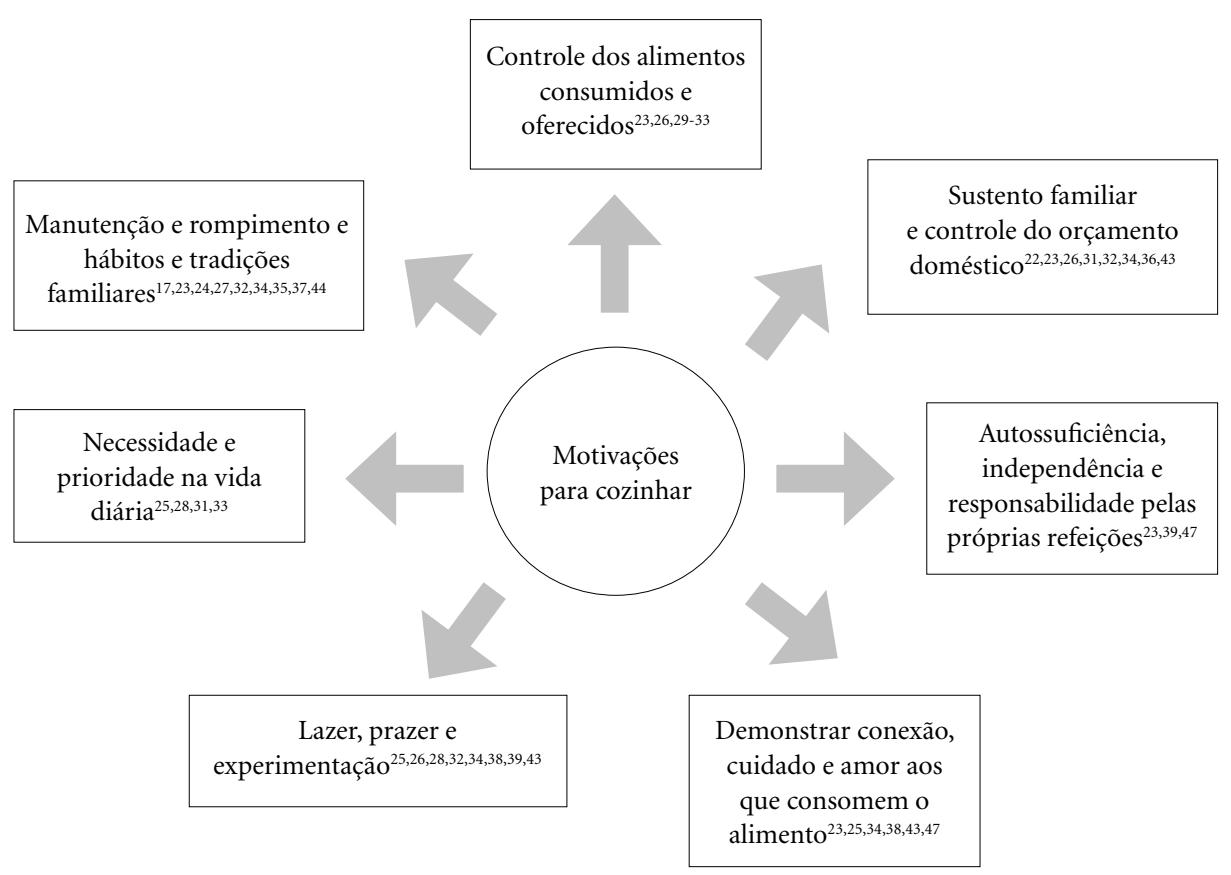

Figura 2. Diferentes motivações para cozinhar identificadas nos resultados de estudos qualitativos sobre o ato de cozinhar no ambiente doméstico submetidos à análise temática.

Fonte: as autoras.

Facilitadores

\begin{tabular}{|c|}
\hline $\begin{array}{c}\text { Modelo familiar e contato com atividades } \\
\text { culinárias na infância }{ }^{18,23,26,27,30,32}\end{array}$ \\
\hline $\begin{array}{c}\text { Confiança e familiaridade com técnicas } \\
\text { culinárias }{ }^{25,26,30,41}\end{array}$ \\
\hline \hline $\begin{array}{c}\text { Disponibilidade de alimentos pré- } \\
\text { elaborados, utensílios e equipamentos }\end{array}$ \\
\hline \hline $\begin{array}{c}\text { Capa,3,37 } \\
\text { planejamente de organização e }\end{array}$ \\
\hline \hline Inspiração criativa ${ }^{30}$ \\
\hline \hline Viver sozinho
\end{tabular}

\section{Barreiras}

\begin{tabular}{|c|}
\hline Ausência de modelo familiar ${ }^{26}$ \\
\hline Falta de confiança e habilidades culinárias ${ }^{26,41}$ \\
\hline $\begin{array}{l}\text { Disponibilidade de locais convenientes } \\
\text { para obter e realizar refeições } \\
\end{array}$ \\
\hline Custos dos alimentos frescos ${ }^{30,31}$ \\
\hline $\begin{array}{l}\text { Falta de tempo }{ }^{25,26,30,31,45,48} \\
\quad \text { e interesse } \\
\text { en,30-32,41 }\end{array}$ \\
\hline Viver sozinho ${ }^{31,33,42}$ \\
\hline
\end{tabular}

Figura 3. Facilitadores e barreiras para cozinhar identificados nos resultados de estudos qualitativos sobre o ato de cozinhar no ambiente doméstico submetidos à análise temática

Fonte: as autoras. 
de possuir habilidade e confiança para cozinhar, estando familiarizado com técnicas culinárias básicas. A falta de confiança e de habilidades culinárias foi relatada como uma barreira para cozinhar ${ }^{26,45}$. Adicionalmente, indivíduos destacaram que a capacidade de organização e planejamento, que inclui planejar o que será preparado, organizando o tempo, a compra de alimentos, o preparo do alimento e a limpeza do ambiente também facilitam e favorecem a efetivação do ato de cozi$n n^{23,24,26}$. Para tanto, indivíduos estadunidenses relataram o uso de estratégias como: cozinhar refeições em grandes quantidades e utilizar as sobras; preparar ou processar os ingredientes com antecedência ${ }^{24}$. Na Dinamarca, indivíduos optaram por terceirizar a responsabilidade pelo planejamento de refeições e compra de alimentos, aderindo a serviços denominados meal boxes, em que caixas contendo os ingredientes necessários para o preparo do jantar eram entregues em suas residências. Assim, continuavam cozinhando, mas tinham reduzido o esforço de definir o que preparar e de realizar a compra dos ingredientes ${ }^{46}$.

Ainda, indivíduos irlandeses relataram a importância de se ter inspiração criativa, que poderia vir por meio de receitas, experiências em restaurantes ou durante as compras em supermercado $^{23}$. Entre britânicos, de diferentes faixas de renda, a disponibilidade de alimentos pré-elaborados, tais como peixes congelados e legumes ou feijões enlatados, bem como de utensílios e equipamentos foram consideradas estratégias úteis para auxiliar no preparo de alimentos no ambiente doméstico ${ }^{28,35,40}$. Esses indivíduos relataram uma dependência crescente, em diferentes graus, em combinações de alimentos básicos com alimentos pré-elaborados, em decorrência da falta de tempo para cozinhar ${ }^{28,35}$.

A falta de tempo figura entre as principais barreiras para cozinhar. Agendas familiares e de trabalho, obrigações de atender às atividades dos filhos e uma série de oportunidades de lazer foram descritos como influências significativas sobre a decisão de (não) cozinhar. O ritmo de vida acelerado e outras demandas muitas vezes não permitiam efetivação dessa prática ${ }^{23,24,26,28,35}$.

A relação entre disponibilidade de locais para compra de alimentos prontos e convenientes e a não efetivação do ato de cozinhar foi observada em estudo conduzido com adultos irlandeses ${ }^{23}$ e adultos jovens estadunidenses ${ }^{26}$. Entre os estadunidenses, o fato de disporem de cantinas universitárias, considerados locais convenientes e favoráveis na economia de tempo foi considerado um fator que torna o preparo de alimentos no ambiente doméstico pouco necessário ${ }^{26}$. Outros estudos identificaram que cozinhar não estava entre as prioridades, preferências ou principais interesses dos indivíduos ${ }^{23,24,27,35,45}$. No Uruguai, por exemplo, indivíduos relaram que não gostavam de cozinhar e, portanto, investiam pouco tempo nessa prática, especialmente em cozinhar do zero. Alguns relataram que embora gostassem, sentiam-se sobrecarregados em ter que cozinhar todos os dias ${ }^{45}$

O custo dos alimentos frescos, especialmente frutas, vegetais e carnes é considerado um desafio para o preparo de refeições no ambiente doméstico. Nesse sentido, indivíduos irlandeses e estadunidenses relataram realizar trocas entre alimentos frescos por produtos mais baratos, porém mais processados ${ }^{23,24}$.

As mudanças nas estruturas das famílias e dos domicílios também pareceram influenciar o hábito de cozinhar. Viver sozinho foi relatado, entre mulheres idosas britânicas ${ }^{47}$, adultos britânicos ${ }^{28}$ e estadunidenses ${ }^{24}$ como uma razão para não querer cozinhar para apenas uma pessoa. Por outro lado, indivíduos britânicos ${ }^{28,35}$, relataram que morar sozinho também era uma forma de estimular o desenvolvimento do hábito de cozinhar.

\section{Discussão e considerações finais}

O presente estudo apresentou, a partir de uma revisão de estudos qualitativos, diferentes aspectos relacionados a cozinhar do ponto de vista dos participantes dos estudos. Os estudos identificados assinalaram que os indivíduos planejam e executam o ato de cozinhar de formas variadas e que cozinhar também é entendido de forma ampla e diversa, englobando desde definições mais restritivas até outras mais inclusivas. Olhando para essas definições de uma perspectiva do grau de processamento de alimentos é possível considerar que para alguns indivíduos cozinhar pressupõe o uso exclusivo de alimentos in natura, minimamente processados e ingredientes culinários e para outros cozinhar inclui também o uso de alimentos processados e ultraprocessados ${ }^{48}$. Assim, os resultados indicam que o conceito de cozinhar não é compreendido uniformemente entre os sujeitos. Cozinhar com maior ou menor grau de complexidade; com ingredientes básicos, crus e frescos, ou com alimentos pré-elaborados não são práticas alimentares facilmente separáveis e distinguíveis ${ }^{15,49}$.

As motivações para cozinhar envolveram tanto questões cognitivas e práticas, quanto questões 
afetivas e emocionais, de modo que estratégias que busquem estimular o ato de cozinhar podem incentivar essa prática não somente a partir de motivações de caráter prático-cognitivo como promover questões nutricionais e econômicas relacionadas à culinária doméstica, mas também a partir dos componentes afetivos do comportamento promovendo a culinária como uma forma de lazer e experimentação.

Seis facilitadores e seis barreiras para cozinhar foram identificados, sendo que alguns deles são ambivalentes, ou seja, apresentam-se como facilitadores ou barreiras, entre eles a presença (ou ausência) de modelo familiar, de confiança e habilidades para cozinhar. O resultado demonstra a importância do contato com indivíduos que cozinhem, bem como do desenvolvimento de confiança e habilidades culinárias ao longo do curso de vida para a efetivação do ato de cozinhar. Sugere-se que novos estudos sejam conduzidos no sentido de compreender como as habilidades culinárias são adquiridas, de modo a informar e facilitar as estratégias focadas em desenvolvê-las. Tais estratégias podem obter melhores resultados se abordarem temáticas relacionadas a outros fatores influenciadores identificados nessa revisão tais como, inspiração criativa para cozinhar e organização e planejamento de refeições no ambiente doméstico. Para tanto, é preciso considerar conceitos ampliados de habilidades culinárias e alimentares, que vão além das habilidades técnicas e mecânicas ${ }^{49,50}$.

Do mesmo modo, morar sozinho apresentou-se tanto como um facilitador como uma barreira, o que sugere a necessidade de novos estudos que busquem compreender as motivações de indivíduos que vivem sozinhos para (não) cozinhar.

Falta de tempo e de interesse aparecem como barreiras. De fato, a sensação crônica de falta de tempo é relatada na literatura como influência na redução do tempo dedicado ao preparo e ao consumo de refeições ${ }^{4,51}$, e pode estar relacionada ao prazer do indivíduo ao cozinhar. Autores identificaram que indivíduos que gostam de cozinhar percebem menos o tempo como uma barreira e tendem a passar mais tempo cozinhando ${ }^{48}$.

O custo dos alimentos frescos foi identificado como uma barreira importante para cozinhar no ambiente doméstico, reiterando o papel da renda e do acesso financeiro como importantes determinantes para escolhas alimentares ${ }^{52,53}$.

As diferentes barreiras identificadas ratificam a compreensão de que os determinantes relacionados ao hábito de cozinhar no ambiente do- méstico são mais complexos do que a presença de habilidades culinárias ${ }^{54}$.

A disponibilidade de alimentos pré-elaborados aparece como um facilitador para cozinhar em casa, mas neste grupo podem estar sendo considerados tanto alimentos processados (por exemplo: tomate pelado enlatado), os quais poderiam, segundo o Guia Alimentar para População Brasileira $^{12}$ compor uma alimentação adequada e saudável, quanto alimentos ultraprocessados (por exemplo: molho de tomate contendo amido e aditivos alimentares), os quais deveriam ser limitados na alimentação. Por ser muito abrangente, o conceito de alimento pré-elaborado não discrimina o grau de processamento, o qual somente pode ser verificado pela lista de ingredientes descrita nos rótulos de alimentos. Esse resultado demonstra a necessidade de que os indivíduos sejam capazes de compreender rótulos de alimentos e de que as informações disponíveis sejam claras e fidedignas para possibilitar a avaliação dos produtos e consequentemente a realização de decisões informadas ao definir os produtos que irão compor a refeição a ser preparada ${ }^{12,48}$.

A disponibilidade de locais convenientes para realizar refeições aparece como uma barreira ao ato de cozinhar. Tendo em vista o objetivo de garantir uma alimentação adequada e saudável à população, o resultado salienta a necessidade de monitorar a qualidade nutricional dos alimentos preparados e distribuídos fora do ambiente doméstico, bem como garantir o fornecimento de informações alimentares qualitativas das refeições produzidas, auxiliando os indivíduos em suas escolhas alimentares ${ }^{5-57}$.

É importante notar que esta revisão foi realizada a partir de estudos conduzidos em diferentes momentos, com diferentes indivíduos e locais (exemplo: homens e mulheres; adultos jovens e idosos; países orientais e ocidentais; países desenvolvidos e em desenvolvimento; área rural e urbana; etc.), portanto os resultados apresentados são influenciados por uma série de fatores contextuais, tais como questões culturais, sociais, temporais e históricas. Analisar essas diferenças não foi objetivo do presente estudo, o que pode se constituir em uma limitação. No entanto, a compilação permitiu demonstrar diferentes percepções relacionadas ao ato de cozinhar, contribuindo para aprofundar a discussão acerca do tema.

Observou-se que a maioria dos estudos foi conduzida em países de língua inglesa, os quais partilham características históricas, políticas e culturais atribuídas à influência do Reino Unido. 
Nesse sentido, observa-se uma lacuna em termos de estudos em outras populações para melhor compreensão das percepções relacionadas ao ato de cozinhar ${ }^{24}$, tendo em vista que essa é uma prática culturalmente definida ${ }^{22,54}$ e influenciada pelos diferentes graus de inserção de indústrias de alimentos transacionais e corporações de varejo e fast food nos países ${ }^{58}$.

A predominância de publicação de estudos de países de língua inglesa pode estar relacionada à centralidade dessa língua no âmbito da ciência, o que facilitaria a publicação de estudos produzidos por pesquisadores que tem o inglês como língua-mãe. Ainda, estudos conduzidos em outros países podem não ter sido captados uma vez que a busca foi realizada somente em português e inglês, possivelmente não identificando estudos publicados em outros idiomas tais como francês, italiano ou espanhol sem publicação simultânea de um resumo em inglês.

No entanto, o uso de diferentes termos na busca sistemática ampliou o alcance da busca, o que constitui um ponto forte uma vez que diferentes terminologias e conceitos são comumente utilizados em pesquisa qualitativa, dificultando a síntese de artigos relacionados a uma mesma temática. O intuito de incluir estudos com objetivos diversos não foi homogeneizar o entendimento sobre a temática, mas tão somente apresentá-la a partir de diferentes olhares. Muitas vezes o ato de cozinhar não se encontrava como objeto central do estudo, mas aparecia como resultado o qual somente foi identificado pela leitura criteriosa dos estudos na íntegra. Tal abordagem permitiu ampliar a compreensão sobre o ato de cozinhar, discutindo as motivações, as influências e a forma como indivíduos se relacionam com essa prática.

A análise dos artigos selecionados levou a reflexões sobre possíveis questões que podem ser exploradas em novos estudos, no sentido de compreender como o hábito de cozinhar se desenvolve ao longo do curso de vida, ou ainda quais motivações levam indivíduos que vivem sozinhos a cozinhar (ou não). Também seria interessante conhecer as motivações e o comportamento de indivíduos que superam as restrições temporais e desenvolvem o hábito de cozinhar.

A presente revisão indica que orientações e intervenções relevantes para a efetivação do ato de cozinhar podem abordar não somente questões cognitivas e práticas, mas também afetivas e emocionais. Sugere-se a adoção de uma perspectiva ampliada sobre o ato de cozinhar que reconheça as diferentes percepções dos indivíduos sobre ele e a complexidade das atividades nele envolvidas, tais como a importância de conseguir planejar e organizar as práticas culinárias, de combinar alimentos pré-elaborados com alimentos in natura e de obter inspiração criativa. Estratégias que envolvam desde a organização e o planejamento até a execução propriamente dita podem ser mais eficientes. A efetivação do ato de cozinhar também pode ser facilitada a partir da redução de barreiras tais como o custo de alimentos frescos e da falta de tempo e de interesse para cozinhar.

\section{Colaboradores}

AC Mazzonetto participou da concepção do estudo, delineamento, realização da busca, seleção dos artigos, análise e interpretação dos dados e redação do manuscrito. M Dean participou na concepção e delineamento do estudo. GMR Fiates participou da concepção do estudo, seleção dos artigos, análise e interpretação dos dados e na revisão crítica do artigo. 


\section{Referências}

1. Warde A, Cheng S-L, Olsen W, Southerton D. Changes in the practice of eating. Acta Sociologica 2007; 50(4):363-385.

2. Moser A. Food preparation patterns in german family households. An econometric approach with time budget data. Appetite 2010; 55(1):99-107.

3. Hamrick KS, Andrews M, Guthrie J, Hopkins D, McClelland K. How much time do americans spend on food?. Washington: U.S. Department of Agriculture, Economic Research Service; 2011.

4. Soliah LAL, Walter JM, Jones SA. Benefits and barriers to healthful eating: What are the consequences of decreased food preparation ability? Am J Lifestyle Med 2012; 6(2):152-158.

5. Caraher M, Lang T. Can't cook, won't cook: A review of cooking skills and their relevance to health promotion. Int J Health Promot Edu 1999; 37(3):89-100.

6. Caraher M, Lange T, Dixon P. The influence of tv and celebrity chefs on public attitudes and behavior among the english public. J Study Food Soc 2000; 4(1):27-46.

7. Caraher M, Seeley A. Cooking in schools: Lessons from the uk. J Home Economics Institute Austr 2010; 17(1):2-9.

8. Caraher MD, Dixon P, Carr-Hill R, Lang T. The state of cooking in england: The relationship of cooking skills to food choice. Br Food J 1999; 101(8):590-609.

9. Brasil. Ministério do Desenvolvimento Social e Combate à Fome (MDS). Marco de referência de educação alimentar e nutricional para as políticas públicas. Brasília: MDS; 2012.

10. Monteiro CA. Nutrition and health. The issue is not food, nor nutrients, so much as processing. Public Health Nutr 2009; 12(5):729-731.

11. Monteiro CA, Levy RB, Claro RM, Castro IRRd, Cannon G. A new classification of foods based on the extent and purpose of their processing. Cad Saúde Pública 2010; 26:2039-2049.

12. Brasil Ministério da Saúde (MS). Guia alimentar para a população brasileira. Brasília: MS; 2014.

13. Reicks M, Trofholz AC, Stang JS, Laska MN. Impact of cooking and home food preparation interventions among adults: Outcomes and implications forfuture programs. J Nutr Educ Behav 2014; 46(4):259-276.

14. Hollywood L, Surgenor D, Reicks M, McGowan L, Lavelle F, Spence M, Raats M, McCloat A, Mooney E, Caraher M, Dean M. Identification of behavior change techniques applied in interventions to improve cooking skills and food skills among adults. Crit Rev Food Sci Nutr 2018: 58(17):2882-2895.

15. Short F. Domestisc cooking skills what are they? HEIA 2003; 10(3):13-22.

16. Short F. Kitchen secrets: The meaning of cooking in everyday life. Oxford: Bloomsbury Academic; 2006.

17. Meah A, Watson M. Saints and slackers: Challenging discourses about the decline of domestic cooking. Sociol Res Online 2011; 16(2):108-120.

18. Halkier B. Suitable cooking?: Performances and positionings in cooking practices among danish women. Food Cult Soc 2009; 12(3):357-377.
19. Strauss AL, Corbin J. Pesquisa qualitativa: Técnicas e procedimentos para o desenvolvimento de teoria fundamentada. Porto Alegre: Artmed; 2008.

20. Mendes KDS, Silveira RCdCP, Galvão CM. Revisão integrativa: Método de pesquisa para a incorporação de evidências na saúde e na enfermagem. Texto Contexto Enferm 2008; 17(4):758-764.

21. Braun V, Clarke V. Using thematic analysis in psychology. Qualitative Res Psychol 2006; 3(2):77-101.

22. Gatley A. The significance of culinary cultures to diet. Br Food J 2016; 118(1):40-59.

23. Lavelle F, McGowan L, Spence M, Caraher M, Raats MM, Hollywood L, McDowell D, McCloat A, Mooney E, Dean M. Barriers and facilitators to cooking from 'scratch' using basic or raw ingredients: A qualitative interview study. Appetite 2016; 107:383-391.

24. Wolfson JA, Bleich SN, Smith KC, Frattaroli S. What does cooking mean to you?: Perceptions of cooking and factors related to cooking behavior. Appetite 2016; 97:146-154.

25. Pollan M. Cozinhar: Uma história natural da transformação. Rio de Janeiro: Editora Intrinseca; 2014.

26. Jones SA, Walter J, Soliah L, Phifer JT. Perceived motivators to home food preparation: Focus group findings. J Acad Nutri Diet 2014; 114(10):1552-1556.

27. Bostic SM, McClain AC. Older adults' cooking trajectories: Shifting skills and strategies. Br Food J 2017; 119(5):1102-1115.

28. Mills S, White M, Wrieden W, Brown H, Stead M, Adams J. Home food preparation practices, experiences and perceptions: A qualitative interview study with photo-elicitation. PLoS One 2017; 12(8):e0182842.

29. Simmons D, Chapman GE. The significance of home cooking within families. Br Food J 2012; 114(8):11841195.

30. Diez-Garcia RW, Castro IRR. A culinária como objeto de estudo e de intervenção no campo da alimentação e nutrição. Cien Saúde Colet 2011; 16(1):91-98.

31. Engler-Stringer R. The domestic foodscapes of young low-income women in montreal: Cooking practices in the context of an increasingly processed food supply. Health Educ Behav 2010; 37(2):211-226.

32. Moisio R, Arnould EJ, Price LL. Between mothers and markets: Constructing family identity through homemade food. J Consum Cult 2004; 4(3):361-384.

33. Parsons JM. When convenience is inconvenient: 'Healthy' family foodways and the persistent intersectionalities of gender and class. J Gender Stud 2016; 25(4):382-397.

34. Szabo M. Men nurturing through food: Challenging gender dichotomies around domestic cooking. J Gender Stud 2014; 23(1):18-31.

35. Gatley A, Caraher M, Lang T. A qualitative, cross cultural examination of attitudes and behaviour in relation to cooking habits in france and britain. Appetite 2014; 75:71-81.

36. Szabo M. "I'm a real catch": The blurring of alternative and hegemonic masculinities in men's talk about home cooking. Women's Stud Int Forum 2014; 44(1):228-235 
37. Liu C. Food practices, gendered intimacy and family life in contemporary guangzhou. Gender Place Cult 2017; 24(1):97-107.

38. Neuman N, Gottzén L, Fjellström C. Narratives of progress: Cooking and gender equality among swedish men. J Gender Stud 2015; 26(2):1-13.

39. Johnson CM, Sharkey JR, McIntosh AW, Dean WR. "I'm the momma": Using photo-elicitation to understand matrilineal influence on family food choice. BMC Womens Health 2010; 10:21.

40. Meah A, Jackson P. Crowded kitchens: The 'democratisation' of domesticity? Gender Place Cult 2013; 20(5):578-596.

41. Bowen RL, Devine CM. "Watching a person who knows how to cook, you'll learn a lot" linked lives, cultural transmission, and the food choices of puerto rican girls. Appetite 2011; 56(2):290-298.

42. Bailey A. The migrant suitcase: Food, belonging and commensality among indian migrants in the netherlands. Appetite 2017; 110:51-60.

43. Gram M, Hogg M, Blichfeldt BS, MacLaran P. Intergenerational relationships and food consumption: The stories of young adults leaving home. Young Consum 2015; 16(1):71-84.

44. Sharif MSM, Zahari MSM, Nor NM, Muhammad R. How could the transfer of food knowledge be passed down? Procedia Soc Behav Sci 2013; 105:429-437.

45. Machin L, Aschemann-Witzel J, Patino A, Moratorio X, Bandeira E, Curutchet MR, Martínez J, Bove I, Molina V, Giménez A, Ares G. Barriers and facilitators to implementing the uruguayan dietary guidelines in everyday life: A citizen perspective. Health Educ Behav 2018: 45(5):511-523.

46. Hertz FD, Halkier B. Meal box schemes a convenient way to avoid convenience food? Uses and understand ings of meal box schemes among danish consumers. Appetite 2017; 114:232-239.

47. Lane K, Poland F, Fleming S, Lambert N, MacDonald H, Potter J, Raats M, Skidmore P, Vince C, Wellings A, Hooper L. Older women's reduced contact with food in the changes around food experience (cafe) study: Choices, adaptations and dynamism. Ageing Soc 2014; 34(4):645-669.

48. Monteiro CA, Cannon G, Levy R, Moubarac J-C, Jaime P, Martins AP, Canella D, Louzada M, Parra D. NOVA. The star shines bright. Food classification. Public health. World Nutrition 2016; 7(1-3):28-38.

49. McGowan L, Caraher M, Raats M, Lavelle F, Hollywood L, McDowell D, Spence M, McCloat A, Mooney E, Dean M. Domestic cooking and food skills: A review. Crit Rev Food Sci Nutr 2017; 57(11):2412-2431.

50. Jomori MM, Vasconcelos FAG, Bernardo GL, Uggioni PL, Proença RPC. The concept of cooking skills: A review with contributions to the scientific debate. Braz J Nutr 2018; 31:83-96.

51. Jabs J, Devine CM. Time scarcity and food choices: An overview. Appetite 2006; 47(2):196-204.

52. Hough G, Sosa M. Food choice in low income populations - a review. Food Qual Preference 2015; 40:334342 .
53. Ver Ploeg M, Wilde PE. How do food retail choices vary within and between food retail environments? Food Policy 2018; 79:300-308.

54. Mills S, White M, Brown H, Wrieden W, Kwasnicka D, Halligan J, Robalino S, Adams J. Health and socia determinants and outcomes of home cooking: A systematic review of observational studies. Appetite 2017; 111:116-134.

55. Fernandes AC, Oliveira RC, Proenca RP, Curioni CC, Rodrigues VM, Fiates GM. Influence of menu labeling on food choices in real-life settings: A systematic review. Nutr Rev 2016; 74(8):534-548.

56. Oliveira RC, Fernandes AC, Proença RPC, Hartwell H, Rodrigues VM, Fiates GMR. Preferences for menu labelling formats of young adults in brazil and in the united kingdom. Rev Nutr 2017; 30(3):321-332.

57. Fernandes AC, Oliveira RC, Rodrigues VM, Fiates GMR, Proença RPC. Perceptions of university students regarding calories, food healthiness, and the importance of calorie information in menu labelling. Appetite 2015; 91:173-178.

58. Monteiro CA, Moubarac JC, Cannon G, Ng SW, Popkin B. Ultra-processed products are becoming dominant in the global food system. Obesity Reviews 2013; 14(Supl. 2):21-28.

Artigo apresentado em 08/08/2018

Aprovado em 01/03/2019

Versão final apresentada em 03/03/2019 
